\title{
Molecular Characterization and Functional Analysis of PR-1-Like Proteins Identified from the Wheat Head Blight Fungus Fusarium graminearum
}

\author{
Shunwen $\mathrm{Lu}^{\dagger}$ and Michael C. Edwards
}

United States Department of Agriculture-Agricultural Research Service, Cereal Crops Research Unit, Fargo, ND 58102-2765.

Accepted for publication 7 November 2017.

ABSTRACT

\begin{abstract}
The group 1 pathogenesis-related (PR-1) proteins originally identified from plants and their homologs are also found in other eukaryotic kingdoms. Studies on nonplant PR-1-like (PR-1L) proteins have been pursued widely in humans and animals but rarely in filamentous ascomycetes. Here, we report the characterization of four PR-1L proteins identified from the ascomycete fungus Fusarium graminearum, the primary cause of Fusarium head blight of wheat and barley (designated FgPR-1L). Molecular cloning revealed that the four FgPR-1L proteins are all encoded by small open reading frames (612 to $909 \mathrm{bp}$ ) that are often interrupted by introns, in contrast to plant $P R-1$ genes that lack introns. Sequence analysis indicated that all FgPR-1L proteins contain the PR-1-specific three-dimensional structure, and one of them features a C-terminal transmembrane (TM) domain that has not been reported for any stand-alone PR-1 proteins. Transcriptional analysis revealed that the four $F g P R-1 L$ genes are expressed in axenic
\end{abstract}

cultures and in planta with different spatial or temporal expression patterns. Phylogenetic analysis indicated that fungal PR-1L proteins fall into three major groups, one of which harbors FgPR-1L-2-related TM-containing proteins from both phytopathogenic and human-pathogenic ascomycetes. Low-temperature sodium dodecyl sulfate polyacrylamide gel electrophoresis and proteolytic assays indicated that the recombinant FgPR-1L-4 protein exists as a monomer and is resistant to subtilisin of the serine protease family. Functional analysis confirmed that deletion of the $F g P R-1 L-4$ gene from the fungal genome results in significantly reduced virulence on susceptible wheat. This study provides the first example that the $F$. graminearum-wheat interaction involves a pathogen-derived PR-1L protein that affects fungal virulence on the host.

Additional keywords: host-pathogen interactions, virulence factors.
The ascomycete pathogen Fusarium graminearum Schwabe is the major cause of Fusarium head blight (FHB), a devastating disease of wheat and barley in North America and worldwide. The disease can result in severe yield losses when environmental conditions are favorable, as seen in the 1990s outbreak in the United States that resulted in an estimated $\$ 1.3$ billion in total direct losses. Moreover, this fungus is notorious for its ability to produce mycotoxins, particularly deoxynivalenol (DON, or vomitoxin), that may contaminate food and feed products, thus posing a health risk to human and animals. The $F$. graminearum-related mycotoxin contamination often leads to significant indirect losses due to the rejection of grains by industry on the basis of strict maximum acceptance levels (as low as $<0.5 \mathrm{ppm}$ ) for DON (Bai and Shaner 2004; Goswami and Kistler 2004, 2005; Kazan et al. 2012; Xu and Nicholson 2009).

The infection of wheat heads by $F$. graminearum is a complex process consisting of distinct phases. Both asexual spores (mainly macroconidia) and sexual spores (ascospores) produced by self-

${ }^{\dagger}$ Corresponding author: S. Lu; E-mail: Shunwen.Lu@ars.usda.gov

This study was supported by USDA-ARS CRIS project 5442-21000-037-00D.

Note: Nucleotide sequence data reported for FgPR- $1 L-1, F g P R-1 L-2, F g P R-1 L-3$, and $F g P R-1 L-4$ are available in the GenBank database under the accession numbers MF001368 to MF001371 for genomic DNA and MF001372 to MF001375 for mRNA, respectively.

Mention of trade names or commercial products in this publication is solely for the purpose of providing specific information and does not imply recommendation or endorsement by the U.S. Department of Agriculture. USDA is an equal opportunity provider and employer.

*The $\boldsymbol{e}$-Xtra logo stands for "electronic extra" and indicates that two supplementary figures and six supplementary tables are published online.

This article is in the public domain and not copyrightable. It may be freely reprinted with customary crediting of the source. The American Phytopathological Society, 2018. mating of this homothallic fungus can initiate infection on the host (Desjardins et al. 2004; Shaner 2003). There is still some uncertainty about whether or not the fungus should be considered "necrotrophic" or "hemibiotrophic", despite recent studies suggesting that the fungus undergoes a "biotrophic" phase (Brown et al. 2010; Jansen et al. 2005; Kazan et al. 2012; Walter et al. 2010). The management of FHB has been a difficult task, with the major means still relying on breeding for resistance, although no fully resistant wheat cultivars are available to date. Quantitative trait loci (e.g., Fhbl)-mediated resistance (Rawat et al. 2016) is known but no gene-for-gene interactions have been identified in the $F$. graminearum-wheat pathosystem (Buerstmayr et al. 2009, 2013). A number of pathogenicity and virulence factors have been characterized from the fungus in previous studies (Hou et al. 2002; Jonkers et al. 2012; Lu et al. 2003; Proctor et al. 1995; Seong et al. 2005; Urban et al. 2015; Voigt et al. 2005; H. Zhang et al. 2016; Y.-Z. Zhang et al. 2016; Zheng et al. 2016) but the molecular mechanisms underpinning FHB still need to be understood. In addition, $F$. graminearum is the causal agent for other diseases on cereal crops; for example, crown root rot of wheat and barley (Backhouse and Burgess 2002) and ear rot of maize(Logrieco et al. 2002; Sutton 1982). Furthermore, the fungus is capable of causing diseases on dicotyledonous plants such as soybean (Martinelli et al. 2004) and Arabidopsis thaliana (Chen et al. 2006).

The genome of $F$. graminearum consists of four chromosomes (total 36.6 Mb) that have been sequenced twice using the North American isolate PH-1 (Cuomo et al. 2007; King et al. 2015). The recent assembly released by the Broad Institute (https://www. broadinstitute.org) includes 13,321 proteins (FGSG_00001 through FGSG_13321). We have previously reported the characterization of 34 small secreted cysteine-rich proteins (SSCP) encoded in the genome of $F$. graminearum that are expressed during the development of FHB based on transcriptional analysis (Lu and Edwards 2016) but the detailed genomic structures, full-length mRNA transcripts, and functions of these SSCP in virulence and pathogenicity have not been determined. These 34 SSCP include one protein 
(FGSG_00569) with homology to the plant group 1 pathogenesisrelated (PR-1) proteins. Because PR-1 proteins are best known as hallmarks of plant defense pathways (van Loon and van Strien 1999; van Loon et al. 2006) and have been shown to mediate host-pathogen interactions (Breen et al. 2016; Lu et al. 2014), we determined to prioritize our further studies on FGSG_00569 and closely related proteins. In the present work, we describe the characterization and functional analysis of FGSG_00569 and three other PR-1-like (PR1L) proteins identified in the $F$. graminearum genome (designated FgPR-1L). We present data showing that the four FgPR-1L proteins all share structure similarities with plant PR-1 proteins but the corresponding $F g P R-1 L$ genes differ greatly in their genomic structures, mRNA processing, and expression patterns. We demonstrate that deletion of one of the $F g P R-1 L$ genes from the genome results in significantly reduced virulence on susceptible wheat. We also show that PR-1L proteins are widespread among filamentous ascomycetes, and one major group includes FgPR-1L-related proteins with C-terminal transmembrane (TM) domains that have not been identified in previous studies. The present study provides the first example that a pathogen-derived PR-1L protein affects virulence of $F$. graminearum on wheat.

\section{MATERIALS AND METHODS}

Fungal isolate and culture conditions. F. graminearum isolate PH-1 used in this study was provided (via Dr. Rubella Goswami) by Dr. Corby Kistler of the United States Department of Agriculture-Agricultural Research Service Cereal Disease Laboratory at St. Paul, MN. For sporulation, the isolate was recovered from glycerol stocks maintained at $-80^{\circ} \mathrm{C}$ and grown on agar plates containing complete medium (CM) (Leach et al. 1982) with salts omitted (CMNOS) or potato dextrose agar (PDA) and incubated in a Percival I-36BLL biological incubator (Percival Scientific, Inc., Perry, IA) at $22^{\circ} \mathrm{C}$ with continuous fluorescent lighting. For liquid cultures, fungal macroconidia were collected from CMNOS or PDA plates and inoculated into $50 \mathrm{ml}$ of CM or minimal medium (MM), which contains glucose as in CM but no nitrogen sources. The inoculated liquid cultures were incubated at room temperature with slow shaking for 2 days and left on the bench for an additional 3 to 12 days before collection of mycelia. Sexual fruiting bodies (perithecia) were obtained by growing the fungus on carrot agar plates for 1 week followed by treatment with $20 \%$ Tween 20 (Sigma-Aldrich, St. Louis), as described by Desjardins et al. (2004).

Nucleic acid preparations. Fungal mycelia were scraped from agar plates or collected from liquid cultures by centrifugation. Spikelets of $F$. graminearum-infected wheat heads were cut into small pieces with all immature seeds removed. The collected fungal mycelia or plant tissues were then transferred into 2-ml Lysing Matrix $\mathrm{D}$ tubes containing 1.4-mm ceramic spheres (QBiogene, Morgan Irvine, CA) and frozen in liquid nitrogen, followed by homogenization using a Mini-Bead-beater-16 Cell Disrupter (BioSpec Products, Bartlesville, OK). DNA was extracted from the homogenized tissues in cetyltrimethylammonium bromide solution (Teknova Inc, Hollister, CA) with chloroform extraction and ethanol precipitation, then finally resuspended in Tris-EDTA buffer ( $\mathrm{pH}$ 8.0) with the concentration adjusted to 10 to $100 \mathrm{ng} / \mu \mathrm{l}$. mRNA was extracted from the homogenized tissues using the Dynabeads mRNA Direct Kit (Invitrogen, Carlsbad, CA) following the manufacturer's instructions and finally eluted in Tris. $\mathrm{HCl}$ buffer ( $\mathrm{pH}$ 8.0). cDNA synthesis was done using the Superscript III first-strand synthesis system (Invitrogen).

Genomic and cDNA clones. Genomic clones of the four $F g P R-1 L$ genes, including the entire open reading frames (ORF) and the $5^{\prime}$ and 3 ' flanking regions (each approximately $1.0 \mathrm{~kb}$ ), were obtained by polymerase chain reaction (PCR) amplification from fungal genomic DNA using primers designed based on the sequences retrieved from the PEDANT genome database (https://www. helmholtz-muenchen.de/ibis/) (Supplementary Table S1). cDNA clones were obtained by reverse-transcriptase (RT)-PCR using primers designed to the genomic sequence. The $5^{\prime}$ and $3^{\prime}$ untranslated regions (UTR) of the FgPR-1L mRNA transcripts were determined using the 5' RACE and 3' RACE System for rapid amplification of cDNA ends (RACE) kits (Invitrogen), respectively. PCR amplifications were performed using conditions described below. Targeted PCR products were cloned into a pCR2.1 vector using the TOPO TA Cloning Kit with TOP10 chemically competent Escherichia coli cells (Invitrogen). Plasmid DNA was prepared using the Wizard Plus SV Minipreps DNA Purification System (Promega Corp., Madison, WI). Sequence identity was determined by DNA sequencing done at the Cornell University Biotechnology Resource Center using gene or vectorspecific primers. Sequences of the genomic and cDNA clones have been deposited into the GenBank database under the accession numbers MF001368 to MF001371 (for genomic DNA) and MF001372 to MF001375 (for mRNA) (Supplementary Table S2).

Gene expression profiling. RT-PCR was performed using purified mRNA samples isolated from designed experiments. For tissue specificity, mRNA samples were isolated from macroconidia (collected from the surface of 2-week-old PDA agar plates), mature perithecia (collected from 4-week-old carrot agar plates), mycelia (harvested from liquid MM culture at $48 \mathrm{~h}$ postinoculation [hpi]), and protoplasts (from those used for fungal transformation described below). For temporal expression in axenic cultures, fungal mRNA samples were isolated from mycelia grown in liquid cultures that were collected by centrifugation. For temporal expression patterns in planta, fungal mRNA samples were isolated along with the host mRNA from wheat heads inoculated with the fungus (see below). The infected heads were collected at 4, 12, 24, and 48 hpi and 4, 8, and 14 days postinoculation (dpi), and the individual splikelets were cut into small pieces and frozen immediately in liquid nitrogen for subsequent mRNA isolation, as described above. DNA oligo primers were designed based on mRNA sequences of individual $F g P R-1 L$ genes and specificity of each set of primers was confirmed by PCR using the plasmid DNA of individual cDNA clones as templates. Concentrations of different cDNA samples were adjusted to be comparable by serial dilutions against the expression level of the $F$. graminearum actin gene (GenBank accession number XM_011328784), which was used as an internal control. All fungal cDNA samples used for gene expression profiling were first tested to be free of genomic DNA contamination. mRNA samples isolated from uninoculated plants were included as controls to check for possible cross-amplification of unrelated wheat genes. PCR was performed in a $25-\mu$ l volume of $1 \times$ GoTaq Green Master Mix (Promega Corp.) that contained $1 \mu \mathrm{l}$ of cDNA and $0.5 \mu \mathrm{M}$ each primer. PCR was started with an initial preheat for $5 \mathrm{~min}$ at $95^{\circ} \mathrm{C}$; followed by 30 to 35 cycles of denaturation at $95^{\circ} \mathrm{C}$ for $15 \mathrm{~s}$, annealing at 55 or $59^{\circ} \mathrm{C}$ for $15 \mathrm{~s}$, and extension at $72^{\circ} \mathrm{C}$ for 1 to $3 \mathrm{~min}$; with a final extension at $72^{\circ} \mathrm{C}$ for $10 \mathrm{~min}$. PCR products were separated on a $1 \%$ agarose/ethidium bromide gel in Tris-acetate-EDTA buffer. To exclude the possibility of cross-amplification of host genes, the amplified PCR products were purified using the QIAquick PCR Purification Kit (Qiagen, Valencia, CA) and sequenced at the Cornell University Biotechnology Resource Center to confirm the identity of the amplicons. All RT-PCR tests were repeated at least twice to verify the observed gene expression patterns.

Expression and characterization of the recombinant FgPR-1L proteins. The coding region corresponding to the individual mature FgPR-1L proteins was PCR amplified from cDNA clones using gene-specific primers with suitable restriction sites incorporated at the $5^{\prime}$ end and subcloned into a pPink $\alpha-\mathrm{HC}$ vector (Invitrogen). The expression construct was transformed into a proteasedeficient strain of Pichia pastoris following the manufacturer's protocols. Protein expression and isolation were done as described previously (Lu et al. 2013). Protein abundance and molecular weight (MW) were determined by sodium dodecyl sulfate polyacrylamide gel electrophoresis (SDS-PAGE) analysis done following standard protocols (Green and Sambrook 2012). The concentration of the target protein was estimated by comparison with a series of dilutions of bovine serum albumin (BSA) (New England Biolabs, Ipswich, MA) included in the 
same SDS-PAGE gel. After SDS-PAGE gel separation, the Coomassie blue-stained bands corresponding to the targeted proteins were excised from the gel and subjected to matrix-assisted laser desorptionionization tandem time of flight (MALDI-TOF/TOF) analysis performed at the Cornell University Biotechnology Resource Center. Dimerization tests and protease resistance assays for the recombinant FgPR-1-L4 protein were done using the methods described previously (Lu et al. 2013).

Targeted gene deletion. The PCR-based split-marker strategy (Catlett et al. 2003; Turgeon et al. 2010) was used to delete individual $F g P R-1 L$ genes from the genome. Genomic sequences $5^{\prime}$ upstream or $3^{\prime}$ downstream of the targeted $F g P R$ - $1 L$ ORF were PCR amplified from the corresponding genomic DNA clone, then fused with respective sequences of the hygromycin $\mathrm{B}(h y g B)$ resistance gene cassette, which was PCR amplified from the plasmid pUCATPH (Lu et al. 1994). Transformation of $F$. graminearum (isolate $\mathrm{PH}-1$ ) was performed using the procedures established for the maize pathogen Cochliobolus heterostrophus, as described previously (Lu et al. 2015; Turgeon et al. 2010). Transformants were purified by isolation of single macroconidia from fungal cultures grown on CMNOS agar plates supplemented with hygB (Sigma-Aldrich) at $100 \mu \mathrm{g} / \mathrm{ml}$. The deletion of the targeted $F g P R-1 L$ gene from the genome was confirmed by PCR screening using gene- or locus-specific primers.

Plant materials and virulence assays. The hexaploid wheat cultivars Wheaton (susceptible) and Sumai 3 (resistant) were obtained through the National Small Grains Collection of the U.S. National Plant Germplasm System. Plants were grown in 6-inch pots (10 to 16 plants/per pot) containing SB100 professional growing mix (Sungrow Horticulture, Bellevue, WA) in the greenhouse or a growth chamber at an average temperature of $21^{\circ} \mathrm{C}$ with a $16-\mathrm{h}$ photoperiod for 4 to 5 weeks until anthesis. For plant inoculation, macroconidia were collected from CMNOS or PDA plates and suspended in $0.05 \%$ Tween 80 solutions. To collect fungal infected plant materials for expression profiling, the concentration of the macroconidial spore suspensions was adjusted to $1 \times 10^{6}$ spores $/ \mathrm{ml}$ and inoculation was done by spreading spore suspensions over the wheat heads with a sprayer. In virulence assays for individual deletion mutants, the concentration of the spore suspensions was adjusted to $1 \times 10^{4}$ spores $/ \mathrm{ml}$ and all individual spikelets on each wheat head were inoculated by manual pipetting (10 $\mu \mathrm{l} / \mathrm{spikelet})$. Control plants were inoculated with the Tween 80 solution only. Inoculated plants were kept in a mist chamber with $100 \%$ humidity for 3 days and then returned to the growth chamber. Disease symptoms were examined 4 to $14 \mathrm{dpi}$. Each treatment included at least 10 plants and was repeated twice. Statistical analysis was done using the $t$ test with raw data processed in an Excel spreadsheet.

Sequence, structural, and phylogenetic analyses. To identify all PR-1L proteins encoded in the genome of $F$. graminearum, the fulllength amino acid sequence of the FGSG_00569 protein described previously (Lu and Edwards 2016) was used as a query for BLAST searches against the National Center for Biotechnology Information (NCBI) nonredundant protein sequence database, and the chromosomal locations of the corresponding coding genes were retrieved through the Gene ID browser (https://www.ncbi.nlm.nih.gov/gene?cmd=Retrieve\&dopt) from the annotated $F$. graminearum genome (Cuomo et al. 2007; King et al. 2015). Amino acid sequence alignments were generated using the MegAlign programs from Lasergene 10.1 software (DNASTAR Inc., Madison, WI). Molecular modeling of the threedimensional structures of the FgPR-1L proteins was done through the PHYRE2 Protein Fold Recognition Server (www.sbg.bio.ic.ac.uk/ $\sim$ phyre2/html) (Kelley et al. 2015). The retrieved Protein Data Bank (PDB) files of FgPR-1L proteins were examined using the Ribbon program (Carson 1997). PR-1L proteins from other fungal species were identified through BLASTP searches (Altschul et al. 1997) using the FgPR-1L protein sequences as queries against the GenBank databases (https://www.ncbi.nlm.nih.gov/). The N-terminal signal peptides of the fungal PR-1L proteins were determined using the SignalP 4.1 Server (www.cbs.dtu.dk/services/SignalP) and the conserved PR-1 domains were determined using the BLAST conserved protein domain (CD) search program (Marchler-Bauer et al. 2017). Phylogenetic analysis was performed using the amino acid sequence alignments of the PR-1 domains generated from the CLUSTALX program (Thompson et al. 1997) and the neighbor-joining method with the PHYLIP 3.696 package (http://evolution.genetics.washington.edu/phylip. html) (Felsenstein 1989). The PHYLIP-generated unrooted consensus tree (from 1,000 bootstrap replicates) was drawn using TreeView software (http://taxonomy.zoology.gla.ac.uk/rod/treeview.html).

\section{RESULTS}

Identification of FgPR-1L proteins. Genomic database searches revealed that the $F$. graminearum genome encodes four proteins (213 to 246 amino acids [aa]) (i.e., FGSG_00569, FGSG_ 02744, FGSG_03109, and FGSG_03312) that all contained PR-1L domains belonging to the sperm-coating protein (SCP) superfamily (cl00133), as defined in the current NCBI CD database (MarchlerBauer et al. 2017). These four proteins were originally annotated as hypothetical (or unnamed) proteins in the NCBI and Munich Information Services for Protein Sequences databases. FGSG_ 00569 was included in our previous study because it falls into the defined SSCP category but has not been characterized further (Lu and Edwards 2016). For convenience, we designated these four PR1L proteins as FgPR-1L-1, FgPR-1L-2, FgPR-1L-3, and FgPR-1L4 , respectively. The four proteins all contained an N-terminal signal peptide and a single PR-1L domain (125 to 145 aa), and two of them (FgPR-1L-1 and -2) also contained C-terminal extensions (CTE) with 35 and 58 residues, respectively. No functional domains were recognizable in the 58-aa CTE of the FgPR-1L-1 protein but a TM domain with 23 residues (GAFTTRPGVGLALIVFLGYIVIF) was identified in the CTE of the FgPR-1L-2 protein (Table 1; Fig. 1A). Further analysis revealed that this TM domain was conserved in FgPR-1L-2 and its homologs from a number of different species of filamentous ascomycetes (Supplementary Fig. S1). FgPR-1L-1, FgPR-1L-2, and FgPR-1L-4 were found to be acidic, with the

TABLE 1. Characteristics of the four group 1 pathogenesis-related (PR-1)-like proteins identified from Fusarium graminearum

\begin{tabular}{|c|c|c|c|c|c|c|c|c|}
\hline \multirow[b]{2}{*}{ Protein } & \multirow[b]{2}{*}{ Accession $^{\mathrm{b}}$} & \multicolumn{7}{|c|}{ Domain composition $^{a}$} \\
\hline & & $\mathrm{Size}^{\mathrm{c}}$ & $\mathrm{MW}^{\mathrm{d}}$ & $\mathrm{pI}^{\mathrm{e}}$ & SP & PR-1 & CTE & Cysteines $^{\mathrm{f}}$ \\
\hline FgPR-1L-1 & MF001372 & 213 & 21.9 & 4.7 & 24 & 125 & 58 & $5(2.5)[4 / 6]$ \\
\hline FgPR-1L-2 & MF001373 & 203 & 20.7 & 4.5 & 18 & 127 & $35 *$ & $4(2.2)[1 / 4 / 5 / 6]$ \\
\hline FgPR-1L-3 & MF001374 & 268 & 26.5 & 8.7 & 24 & 145 & $\ldots$ & $2(0.8)[\mathrm{NA}]$ \\
\hline FgPR-1L-4 & MF001375 & 246 & 24.8 & 5.6 & 17 & 136 & $\ldots$ & $1(0.4)$ [NA] \\
\hline
\end{tabular}

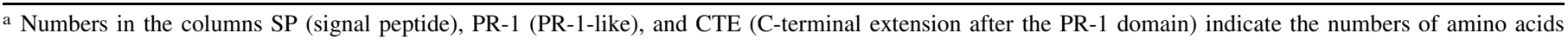
comprising the conserved domains (if any). An asterisk(*) indicates the presence of a transmembrane domain in the FgPR-1L-2 protein.

b GenBank accession numbers.

c Size indicates the number of amino acids in the full-length FgPR-1L proteins.

d Molecular weight (in kilodaltons), calculated based on the mature FgPR-1L proteins.

e Isoelectric points, calculated based on the mature proteins.

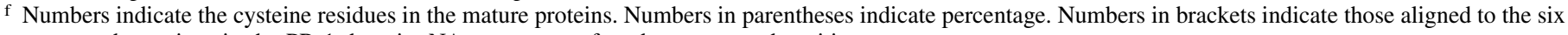
conserved cysteines in the PR-1 domain. NA = none was found at conserved positions. 
predicted isoelectric points (pI) 4.5 to 5.6 , and FgPR-1L-3 to be basic, with a $\mathrm{pI}>8.0$ (Table 1 ).

BLASTP searches against the nonredundant plant protein database (taxid: 3193 ) indicated that all FgPR-1L proteins (except for FgPR-1L-1) have significant similarities $(\mathrm{E}$ value $=1 \mathrm{e}-18$ to $3 \mathrm{e}-32)$ to PR-1 proteins identified from various plant species (data not shown). Further comparative analysis indicated that the similarities of the FgPR-1L proteins to the tomato P14a protein (Fernández et al. 1997), which represents the plant PR-1 subfamily in the SCP superfamily, may be even greater than similarities to the PR-1L proteins representing the other five eukaryotic SCP subfamilies or the Cys-rich secretory protein/antigen 5/PR-1 (CAP) family in the NCBI CD database (https://www.ncbi.nlm.nih.gov/Structure/cdd/ wrpsb.cgi) (Supplementary Table S3). Although the four FgPR-1L proteins did not show significant overall similarities to each other, they were all found to contain conserved residues characteristic of the prototype PR-1 domain. The four active sites with two glutamic acid (E) and two histidine (H) residues (Fernández et al. 1997; Szyperski et al. 1998) were found to be strictly conserved in all four proteins. However, the six cysteine (Cys) residues (C1 to $\mathrm{C} 6)$ conserved in plant PR-1 proteins were partially or completely missing in FgPR-1L proteins: FgPR-1L-1 had two Cys residues (C4 and C6), FgPR-1L-2 had four (C1, C4, C5, and C6), and FgPR-1L-3 and FgPR-1L-4 had none (Fig. 1A). Nevertheless, molecular modeling suggested that the PR-1L domains in the four proteins would all adapt three-dimensional structures resembling the canonic PR-1 domain represented by P14a (Fernández et al. 1997) and the human glioma pathogenesis-related protein (Szyperski et al. 1998) that form solvent-exposed spatial clusters consisting of the four active sites that are all recognizable in the FgPR-1L proteins (Fig. 1B).
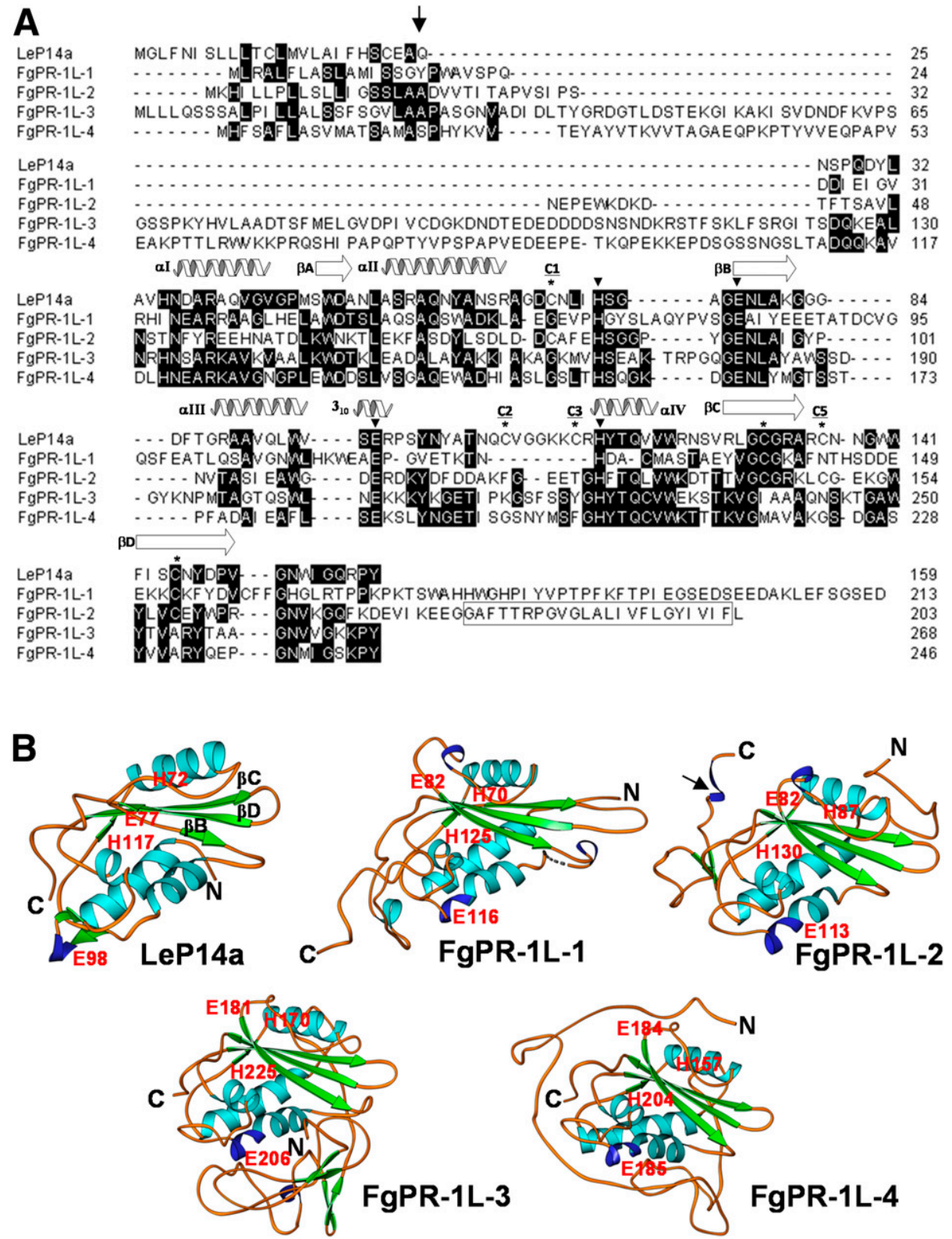

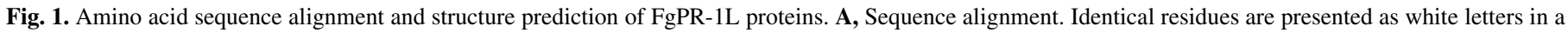

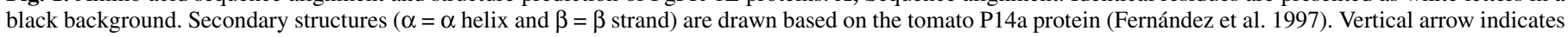

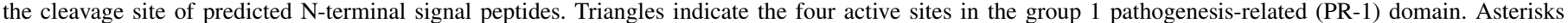

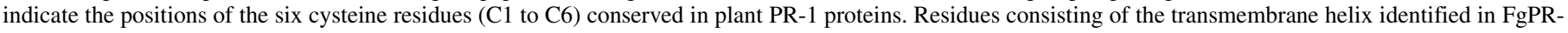

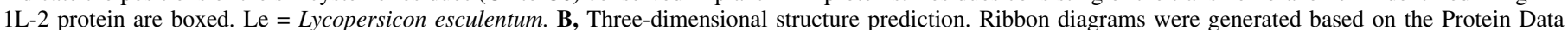

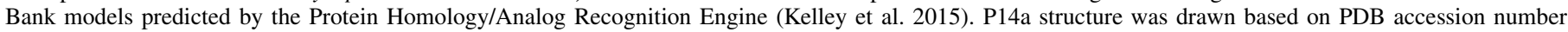

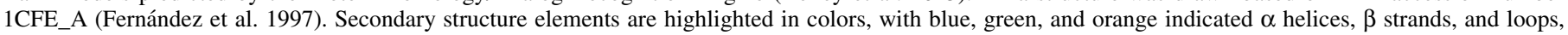

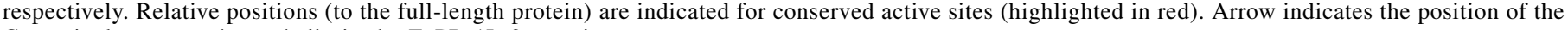
C-terminal transmembrane helix in the FgPR-1L-2 protein. 
Determination of the full-length mRNA transcripts of the FgPR-1L genes. Based on the data obtained from the NCBI Map Viewer Server (https://www.ncbi.nlm.nih.gov/genome), the genes encoding the four FgPR-1L proteins were located on two different chromosomes, with $F g P R-1 L-1$ and -2 on chromosome 1 and $F g P R-1 L-3$ and -4 on chromosome 2 (Fig. 2A). RT-PCR was performed along with $5^{\prime}$ RACE and $3^{\prime}$ RACE cDNA cloning to determine the full-length mRNA transcripts for individual $F g P R-1 L$ genes. It was found that the $F g P R-1 L$ mRNA transcripts consist of 944 to 1,223 nucleotides (nt) with the $5^{\prime}$ UTR, the $3^{\prime}$ UTR, and the polyA tails varying in size from 60 to 429,133 to 201 , and 15 to 19 nt, respectively. The longest 5'UTR (429 nt) and the longest $3^{\prime}$ UTR (201 nt) were found in $F g P R-1 L-1$ and $F g P R-1 L 4$, respectively.

Genomic DNA clones were also obtained for the four $F g P R-1 L$ genes to facilitate targeted gene deletion experiments (see below). It was found that $F g P R-1 L$ genes differed greatly from each other in exon-intron or domain organization and even in $\mathrm{G}+\mathrm{C}$ content. The open reading frames (ORF) of the $F g P R-1 L-1,-3$, and -4 genes were all interrupted by one or two introns, but no introns were found in the ORF of $F g P R-1 L-2$ (Fig. 2B). The $\mathrm{G}+\mathrm{C}$ content in the ORF of the $F g P R-1 L-1,-2$ and -3 genes was typical of ascomycetes (approximately $50 \%$ ), but the ORF of the $F g P R-1 L-4$ gene was apparently $\mathrm{G}+\mathrm{C}$ rich (60\%) (Supplementary Table S4). Noticeably, the introns embedded in the three $F g P R-1 L$ genes were all relatively A+T rich $(\mathrm{G}+\mathrm{C}=33$ to $45 \%)$ in contrast to the exons $(\mathrm{G}+\mathrm{C}=49$ to $62 \%)$ in the same genes. This contrast resembles that observed in certain plant genes (e.g., the wheat TaPr-1-rk genes that all contain A+T-rich introns) (Lu et al. 2017). This commonality supports the hypothesis that "junk" DNA such as intronic sequences may benefit DNA replication or repair because it protects the annealing of singlestranded DNA (Lu 2014).

Phylogenetic relationships of $\mathrm{PR}-1 \mathrm{~L}$ proteins in filamentous ascomycetes. BLAST searches with FgPR-1L proteins as queries against the NCBI nonredundant protein database identified homologous proteins with conserved PR-1L (or SCP) domains from species in all major classes of filamentous ascomycetes. These species included all famous model ascomycetes, whether they are considered to be phytopathogenic (e.g., C. heterostrophus and
Magnaporthe grisea), entomopathogenic (e.g., Beauveria bassiana and Metarhizium anisopliae), or human-pathogenic (e.g., Coccidioides immitis and Histoplasma capsulatum). Like F. graminearum, many species (especially members of class Sordariomycetes) were found to have more than one PR-1L protein, with the maximum up to six, depending on the species examined.

Phylogenetic analysis (Fig. 3) suggested that fungal PR-1L proteins fall into three major groups. Group I consisted of species mainly from the classes Sordariomycetes, Dothideomycetes, and Leotiomycetes, with three recognizable subgroups represented by FgPR-1L-1, FgPR1L-3, and FgPR-1L-4, respectively. Interestingly, the FgPR-1L-1 subgroup contained predominantly species of biological control agents that include both entomopathogenic (e.g., B. bassiana, M. anisopliae, and Tolypocladium ophioglossoides) and mycoparasitic (e.g., Trichoderma atroviride and several other related species) ascomycetes. Group II consisted of species from all four major classes, with one major subgroup represented by FgPR-1L-2. Interestingly, like FgPR-1L-2, most proteins in this subgroup were found to contain a C-terminal TM domain. These TM-containing PR-1L proteins have not been reported for any species of filamentous ascomycetes in previous studies. Noticeably, the majority of Dothideomycetes species, including Cochliobolus and related genera, were found in group II only. Group III also consisted of all four major classes of filamentous ascomycetes but did not contain any proteins from $F$. graminearum despite the presence of several closely related Fusarium spp. (e.g., $F$. langsethiae and $F$. verticillioides), suggesting that one of the PR-1L proteins conserved in the genus Fusarium may have been lost in F. graminearum.

Differential expression of the $F g P R-1 L$ genes. Because it is known that certain fungal $P R-1 L$ genes such as the $S C 7$ genes from the basidiomycete Schizophyllum commune are differentially expressed with tissue specificity (Schuren et al. 1993), we first tested whether any of the $F g P R-1 L$ genes could be expressed in a similar manner. For temporal expression patterns, we used two different axenic culture conditions, the MM and CM, in addition to the in planta condition, because the MM mimics nitrogen-starvation conditions known to be associated with fungal pathogenesis. RTPCR results indicated that the four $F g P R-1 L$ genes are all expressed

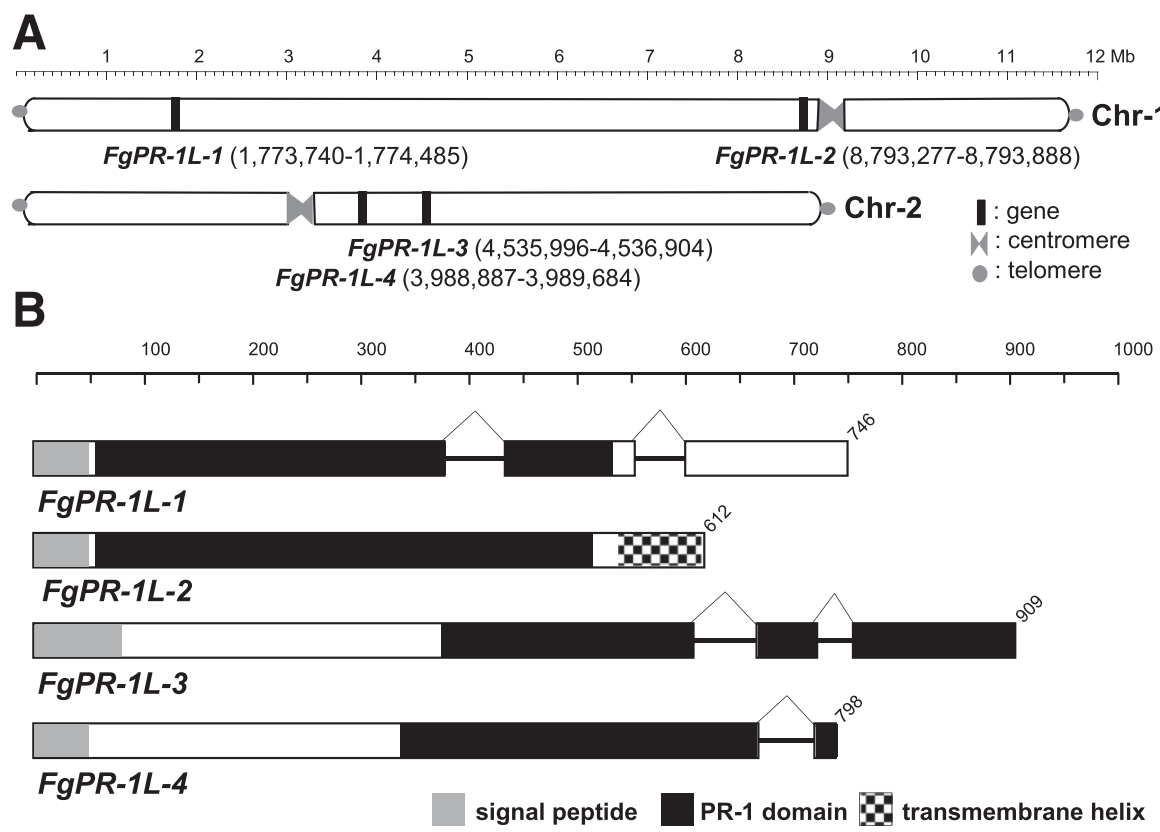

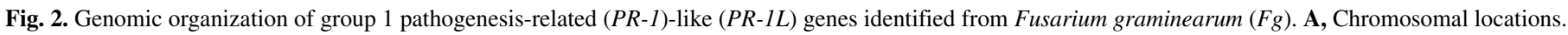

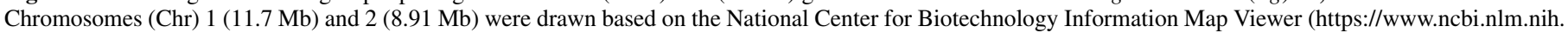

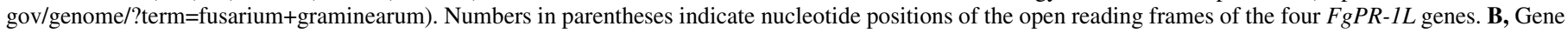

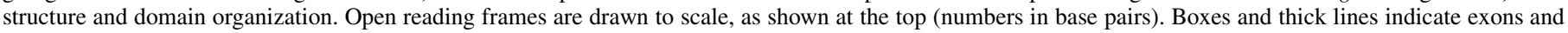

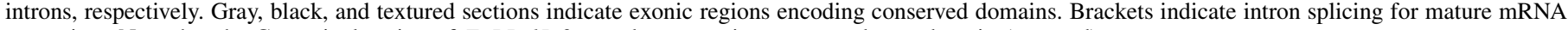
transcripts. Note that the C-terminal region of $F g P R-1 L-2$ encodes a putative transmembrane domain (textured). 
but their expression patterns differ greatly. In the spatial expression patterns (Fig. 4A), transcripts of $F g P R-1 L-1$ were detected at high levels in mature perithecia (the sexual fruiting bodies) but much lower levels in macroconidia, mycelia, and the cell-wall-free protoplasts (Fig. 4A, second row). Transcripts of $F g P R-1 L-2$ were detected at high levels in mycelia and protoplasts but much lower levels in macroconidia and perithecia (Fig. 4A, third row). Transcripts of $F g P R-1 L-3$ were detected in macroconidia and mycelia at high levels but were rarely seen in perithecia and protoplasts (Fig. 4A, fourth row). Transcripts of $F g P R-1 L-4$ were detected in all tissues, with expression levels lower in macroconidia and equally high in the other three types of tissues (Fig. 4A, bottom row).

In the temporal expression patterns for axenic cultures (Fig. 4B), transcripts of $F g P R-1 L-1$ were detected at all time points in both $\mathrm{MM}$ and CM, with expression levels generally low (Fig. 4B, second row). Transcripts of $F g P R-1 L-2$ were detected at all time points, with apparent upregulation at 24 and $48 \mathrm{~h}$ in MM but not in CM cultures (Fig. 4B, third row). Transcripts of $F g P R-1 L-3$ were detected only at 24 and $48 \mathrm{~h}$, with levels much higher in MM than in CM (Fig. 4B, fourth row, compare lanes 3 and 4 with lanes 10 and 11). Transcripts of $F g P R-1 L-4$ were detected at all time points in both MM and CM cultures (Fig. 4B, bottom row).

In the in planta expression patterns (Fig. 4C), transcripts of FgPR-1L-1 were detected at low levels at all time points (Fig. 4C, second row). Transcripts of $F g P R-1 L-2$ were detected with patterns similar to those observed in axenic cultures (Fig. 4C, third row). Transcripts of $F g P R-1 L-3$ were barely detectable, in contrast to the time-point-dependent expression observed in in axenic cultures (Fig. 4C, fourth row). Transcripts of $F g P R-1 L-4$ were detected at high levels at all time points, as observed in axenic cultures (Fig. 4C, bottom row). Overall, no clear differences were found between the expression patterns on resistant (Sumai 3, lanes 1 to 7 ) and susceptible (Wheaton, lanes 10 to 16 ) wheat for any of $F g P R-1 L$ genes. No signals were detected in the control mRNA samples isolated from uninoculated wheat plants (Fig. 4C, lane 18), confirming that all transcripts detected were specific for $F$. graminearum.

Characterization of the recombinant FgPR-1L-4 protein. Recombinant FgPR-1L-4 protein was obtained through heterologous expression in P. pastoris. A single major species with an MW between 25 and $37 \mathrm{kDa}$ along with a minor species near $25 \mathrm{kDa}$ were detected in SDS-PAGE under denaturing conditions (Fig. 5A, lane 4). MALDI-TOF/TOF analysis confirmed that both species consist of FgPR-1L-4-specific peptides (data not shown). The predicted MW for the mature FgPR-1L-4 protein is $24.8 \mathrm{kDa}$ (Table 1), which matches the minor species. The increased MW for the major species may be due to certain posttranslational modifications such as glycosylations known to occur in $P$. pastoris (Bretthauer and Castellino 1999; O'Leary et al. 2004), and such modifications may be

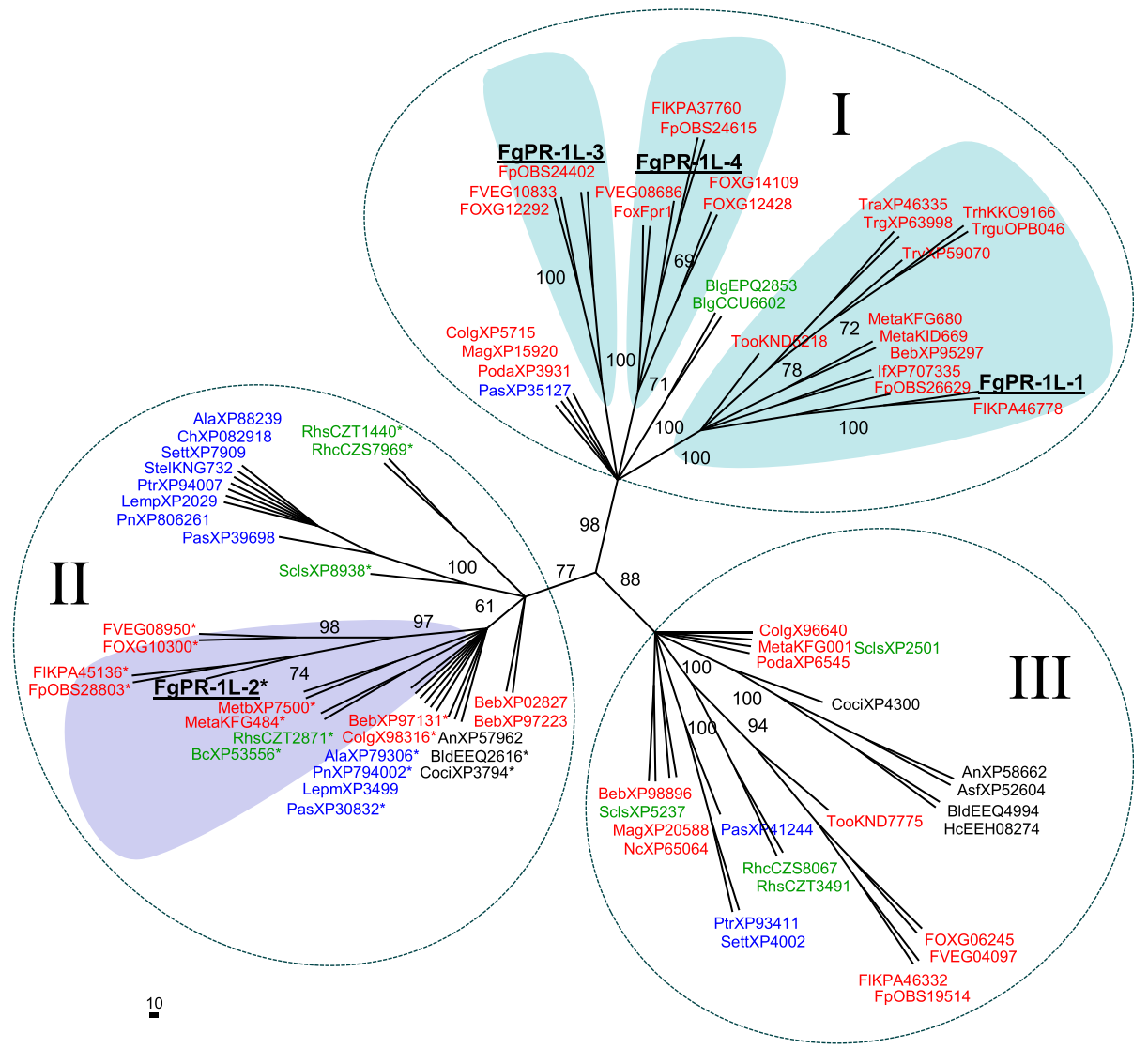

Fig. 3. Phylogenetic relationship of group 1 pathogenesis-related (PR-1)-like proteins identified from filamentous ascomycetes. The neighbor-joining tree was generated based on the conserved sperm-coating protein or PR-1 domain sequences. Bootstrapping values ( $>60 \%$, from 1,000 replicates) are indicated on major branches. Homologs of FgPR-1L proteins (underlined) that were identified from other species of classes Dothideomycetes, Eurotiomycetes, Leotiomycetes, and Sordariomycetes are highlighted in blue, black, green, and red, respectively. The four subgroups represented by FgPR-1L proteins are shaded. Proteins with a Cterminal transmembrane helix are indicated by asterisks. Note that FgPR-1L-1, -3, and -4 are found in "sister" clades in the same group (I), whereas FgPR-1L-2 is located in a different group (II). Species abbreviations for protein names or GenBank accession numbers (shown as simplified forms with the first two to three letters plus the last four to five numbers for convenience): $\mathrm{Af}=$ Aspergillus fumigatus, $\mathrm{Ala}=$ Alternaria alternata, $\mathrm{An}=$ Aspergillus nidulans, $\mathrm{Bc}=$ Botrytis cinerea, $\mathrm{Beb}=$ Beauveria bassiana, $\mathrm{Bld}=$ Blastomyces dermatitidis, $\mathrm{Blg}=$ Blumeria graminis, $\mathrm{Ch}=$ Cochliobolus heterostrophus, Coci $=$ Coccidioides immitis, Colg $=$ Colletotrichum graminicola, $\mathrm{Fg}=$ Fusarium graminearum, $\mathrm{Fl}=F$. langsethiae, $\mathrm{Fox}=F$. oxysporum $\mathrm{f}$. sp. lycopersici, $\mathrm{Fp}=F$. poae, Fve $=F$. verticillioides, $\mathrm{Hc}=$ Histoplasma capsulatum, If = Isaria fumosorosea, $\mathrm{Lepm}=$ Leptosphaeria maculans, $\mathrm{Mag}=$ Magnaporthe grisea, Meta $=$ Metarhizium anisopliae, Metb $=$ M. brunneum, $\mathrm{Nc}=$ Neurospora crassa, Pas $=$ Paraphaeosphaeria sporulosa, $\mathrm{Pn}=$ Parastagonospora nodorum, Poda $=$ Podospora anserina, Psed $=$ Pseudogymnoascus destructans, $\mathrm{Ptr}=$ Pyrenophora tritici-repentis, $\mathrm{Rhc}=$ Rhynchosporium commune, Rhs $=R$. secalis, Scls $=$ Sclerotinia sclerotiorum, Sett $=$ Setosphaeria turcica, Ste $=$ Stemphylium lycopersici, Too $=$ Tolypocladium ophioglossoides, $\operatorname{Tra}=$ Trichoderma atroviride, $\operatorname{Trg}=T$. gamsii, Trgu $=T$. guizhouense, and Trh $=$ T. harzianum. 
incomplete, thus leaving the minor species with "correct" MW. The recombinant FgPR-1L-4 protein was subjected to dimerization and protease resistance tests in comparison with the wheat PR-1 proteins (Lu et al. 2011). In the low-temperature SDS-PAGE analysis, which has been proved to be an acceptable method for detecting monomeric versus dimeric proteins in previous studies (Lorenz et al. 2007; Lu et al. 2008, 2013, 2014; Prados-Rosales et al. 2012), both the major and minor species of the FgPR-1L-4 protein that was kept at $4^{\circ} \mathrm{C}$ were found to migrate to the same positions as the denatured sample (Fig. 5A, compare lanes 1 and 4), in contrast to the dimeric wheat TaPR-1-5 protein, which was found at different positions (Fig. 5A, compare lanes 3 and 6). These results confirmed that FgPR-1L-4 exists as a monomer. In proteolytic assays with subtilisin (a serine protease) (Fig. 5B, upper three rows), the control protein BSA (protease sensitive) was completely digested at $0.8 \mu \mathrm{g} / \mu \mathrm{l}$ (top row). FgPR-1L-4 remained clearly detectable at the same concentration, although it became undetectable at concentrations $>0.8 \mu \mathrm{g} / \mu \mathrm{l}$ (middle row). The TaPR-1-5 protein was detectable with similar intensities at all concentrations (bottom row). In proteolytic assays with papain

A

B

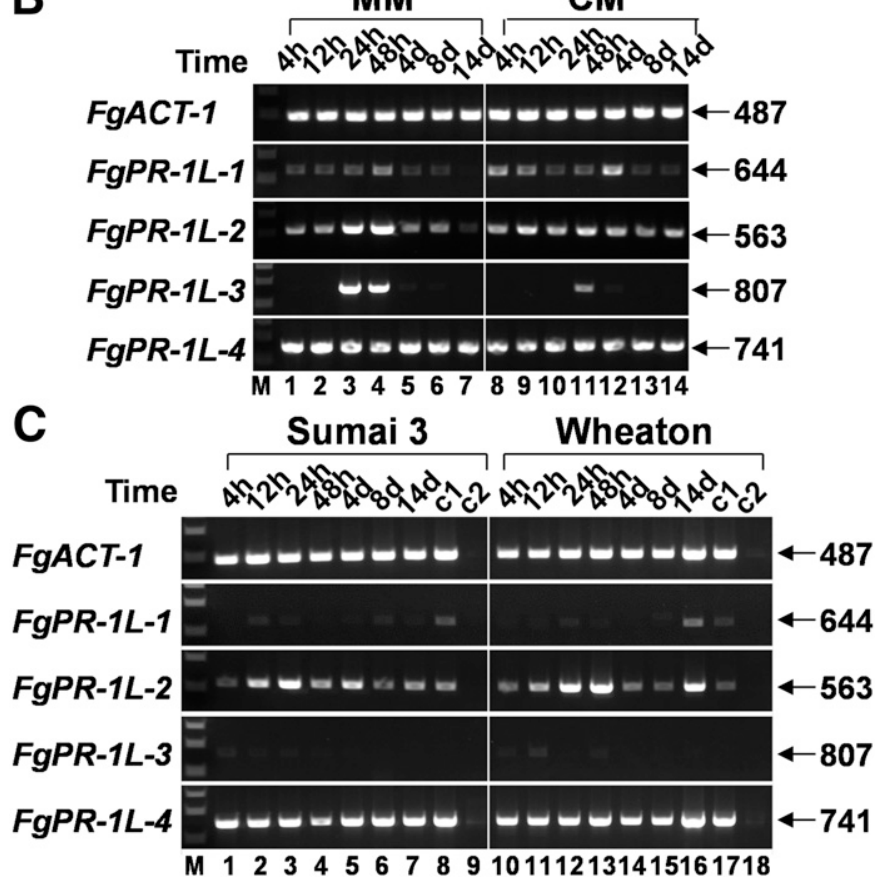

Fig. 4. Spatial and temporal expression patterns of the Fusarium graminearum group 1 pathogenesis-related $(P R-1)$-like genes. Ethidium-bromide-stained $1 \%$ agarose gels were loaded with the amplicons of reverse-transcription polymerase chain reaction products from mRNA isolated from $\mathbf{A}$, different types of fungal cells $(\mathrm{mac}=$ macroconidia, per $=$ perithecia, myc $=$ mycelia, and pro $=$ protoplasts); B, axenic fungal cultures grown in minimal (MM) or complete (CM) media; C, F. graminearum-infected plants of Sumai 3 (resistant) and Wheaton (susceptible). mRNA samples in B and C were collected at 4, 12, 24, and $48 \mathrm{~h}$ postinoculation and 4, 8, and 14 days postinoculation, as indicated at the top. Lanes 8 (c1) and 9 (c2) in B represent fungal culture (MM 4 days) and uninoculated plant controls, respectively. Numbers at arrow indicate the size of amplicons (in base pairs). $F g A C T-1$ ( $F$. graminearum actin gene) was included as internal controls. $\mathrm{M}=1-\mathrm{kb}$ DNA ladder. (a Cys protease) (Fig. 5B, lower three rows), both BSA and FgPR-1L-4 proteins were completely digested at the starting concentration $0.2 \mu \mathrm{g} / \mu \mathrm{l}$ (top and middle rows) in contrast to TaPR-1-5, which remained detectable until $1.6 \mu \mathrm{g} / \mu \mathrm{l}$ (bottom row). These results indicated that the FgPR-1L-4 protein is partially resistant to subtilisin. No necrosis-inducing activities were observed when the recombinant FgPR-1L-4 protein was infiltrated into leaves of either resistant or susceptible wheat plants (data not shown). The same heterologous expression system was also used for expression of the other three FgPR-1L proteins but no recombinant proteins (or some with very low levels) were obtained, making further characterization not feasible.

Deletion of the $F g P R-1 L-4$ gene results in significantly reduced virulence. The complete $\mathrm{ORF}$ of the $F g P R-1 L-4$ gene was deleted from the genome using the split-marker PCR strategy (Catlett et al. 2003; Turgeon et al. 2010) (Fig. 6A, left). Five stable

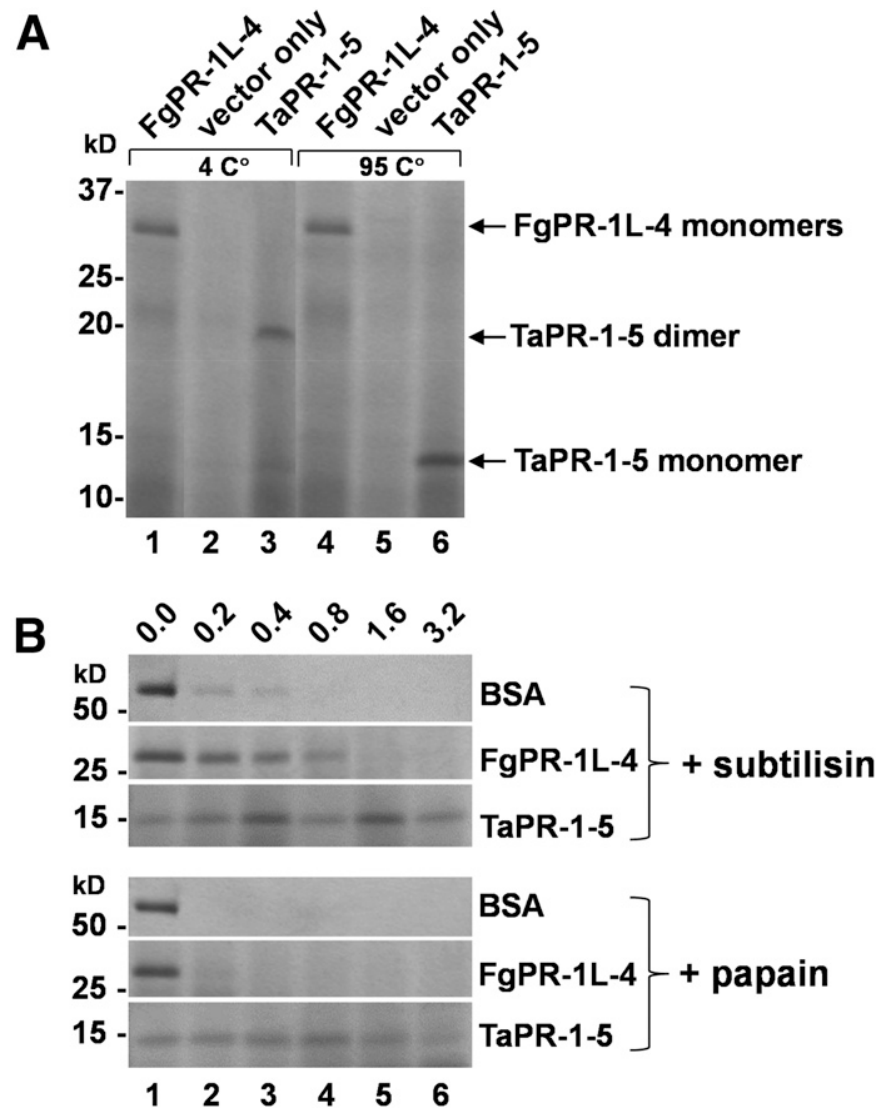

Fig. 5. Characterization of the recombinant FgPR-1L-4 protein. A, Lowtemperature sodium dodecyl sulfate polyacrylamide gel electrophoresis (SDSPAGE) analysis. The gel (15\%) was loaded (approximately $0.5 \mu \mathrm{g}$ per lane) with the recombinant FgPR-1L-4 (lanes 1 and 4) and the plant TaPR-1-5 (Lu et al. 2013) (lanes 3 and 6) proteins and stained with Coomassie blue after electrophoresis. Lanes 2 and 5 were loaded with protein secretions isolated from a yeast strain expressing the cloning vector only that was obtained from the same heterologous expression experiment for FgPR-1L-4. Note that the FgPR-1L-4 protein migrated to the same position (arrow) under nondenaturing $\left(4^{\circ} \mathrm{C}\right.$, lane 3$)$ and denaturing $\left(95^{\circ} \mathrm{C}\right.$, lane 4$)$ conditions, in contrast to the dimeric TaPR-1-5 protein, which showed a sharp molecular weight switch (compare lanes 3 and 6), indicating that FgPR-1L-4 exists as a monomer. B, Proteolytic assays. SDS-PAGE gels were loaded with proteins (approximately $0.5 \mu \mathrm{g}$ per lane) digested with subtilisin (a serine protease) or papain (a cysteine protease) at final concentrations as indicated at the top (micrograms per microliter). Protease-sensitive bovine serum albumin (BSA) was included as a control. Note that BSA was completely digested by subtilisin at 0.8 , at which FgPR-1L-4 was still clearly visible (lane 4, top rows), whereas both proteins were completely digested by papain at 0.2 (lane 2 , bottom rows), suggesting that the monomeric FgPR-1L-4 is partially resistant to serine proteases and not like the dimeric TaPR-1-5 which is highly resistant to proteolytic attacks under the same conditions (lanes 1 to 6 , top and bottom rows). Numbers on the left indicate the molecular masses (in kilodaltons) of protein markers. 
hygB-resistant transformants were obtained and the deletion of the targeted $F g P R-1 L-4$ gene was confirmed by PCR amplification (Fig. 6A, right). The $F g P R-1 L-4$ ORF-specific primer pair (atgF/ tagR) amplified a 798-bp fragment from the wild-type control and the transformant $\mathrm{TxFg} 1210-5-3$ (top row, lanes 1 and 4) but not from the other four transformants (TxFg1210-5-1, 1210-5-2, 1210-5-7, and 1210-5-11) (lanes 2, 3, 5, and 6, respectively). The $h y g B$-specific primer pair ( $\mathrm{pH} 2150 / \mathrm{pH} 1302)$ amplified an 849-bp fragment from all five transformants (second row, lanes 2 to 6 ) but not from the wild-type control (lane 1). The $5^{\prime}$ end-specific primer pair (5FP and pH2664) amplified a 1,411-bp fragment (third row) and the $3^{\prime}$ endspecific primer pair (pH431 and 3RP) amplified a 1,193-bp fragment (bottom row) from TxFg1210-5-1, 1210-5-2, 1210-5-7, and 1210-511 (lanes 2, 3, 5, and 6, respectively) but not from TxFg1210-5-3 (lane 4). These results confirmed that, in TxFg1210-5-1, 1210-5-2, 1210-57, and 1210-5-11, the native $F g P R-1 L-4$ gene was completely deleted due to the homologous integration of the transforming DNA at the targeted locus; whereas, in $\mathrm{TxFg} 1210-5-3$, the native $F g P R-1 L-4$ gene was intact because the transforming DNA integrated at an "ectopic" location in the genome. All four deletion mutants ( $\Delta$ fgpr- $1 l$ 4 ) and the "ectopic" transformant were found to grow normally and produce macroconidia with morphological features like their parental isolate (PH-1), and all were able to produce fertile perithecia when grown on carrot agar plates. Plant assays confirmed that $\Delta f g p r-1 l-4$ mutants sustained significantly reduced virulence, based on the average percentage of bleached spikelets (APBS) on infected heads of susceptible wheat. Under the conditions used in this study, scattered weak disease symptoms (e.g., small brown spots) were observed on inoculated spikelets as early as 72 hpi (data not shown), and the typical FHB symptoms (bleached spikelets) were observed starting at 7 to $8 \mathrm{dpi}$ in all inoculated treatments on susceptible wheat; however, the APBS differed significantly. Plants inoculated with the wild-type isolate (PH-1) or the ectopic transformant $\mathrm{TxFg} 1210-5-3$ developed more bleached spikelets per head (Fig. 6B, spike numbers 1 and 4) than those inoculated with any of the four $\Delta f g p r-1 l-4$ mutants (spike numbers 2, 3, 5, and 6). The calculated APBS (based on the data
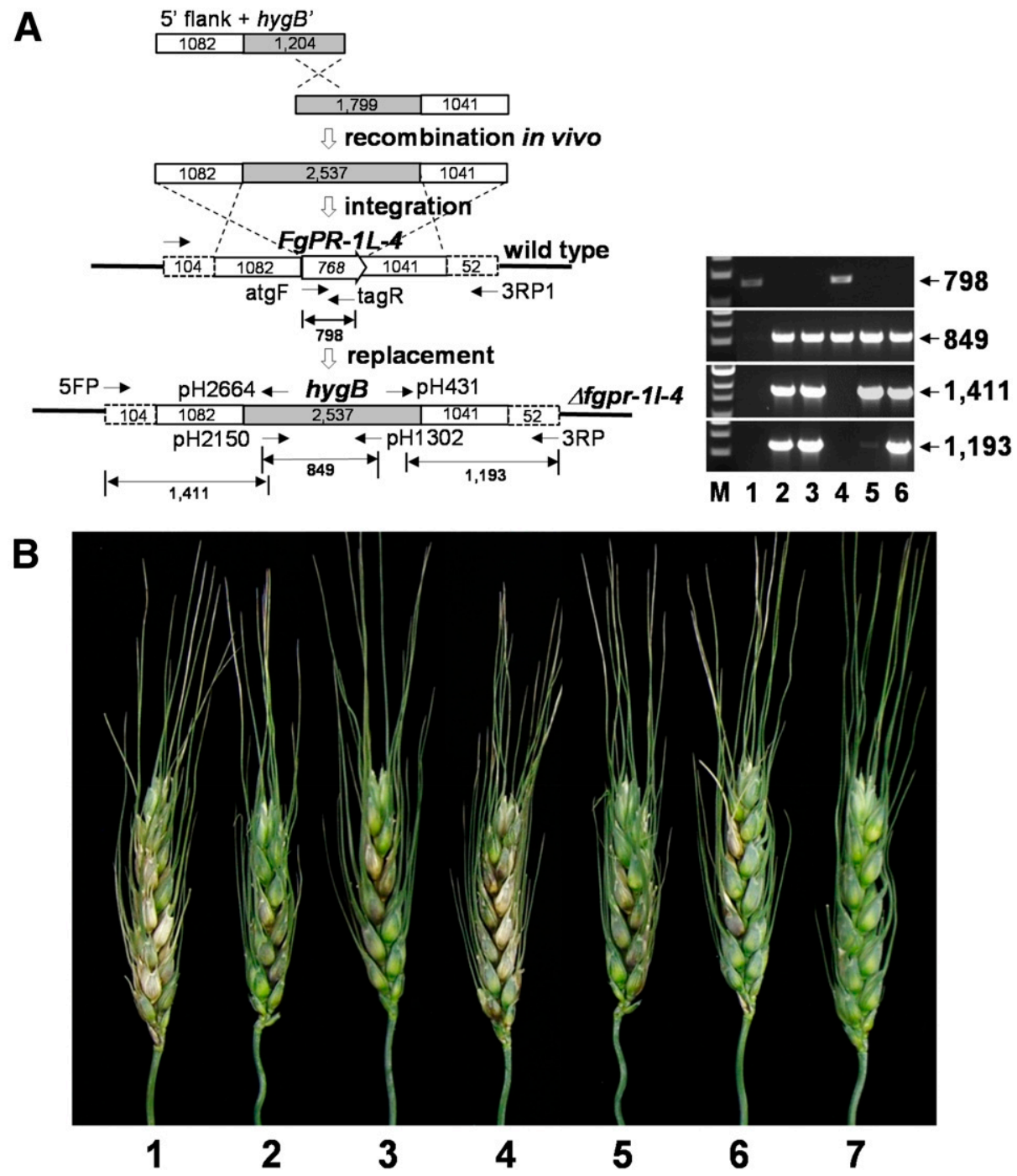

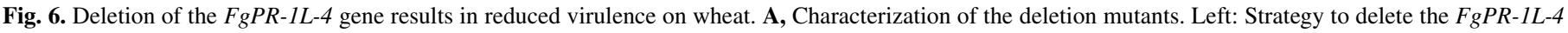

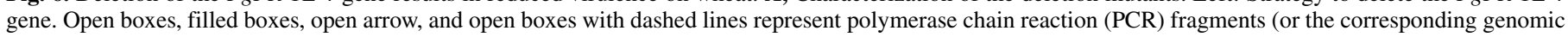

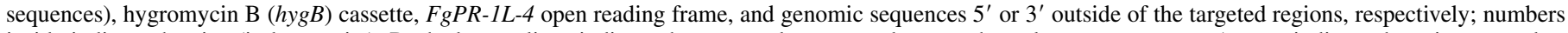

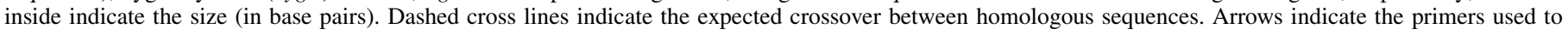

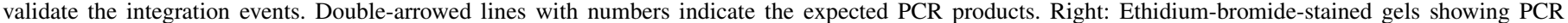

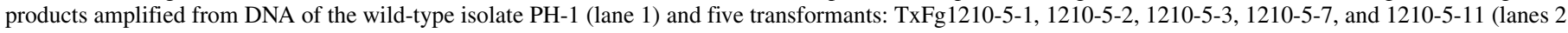

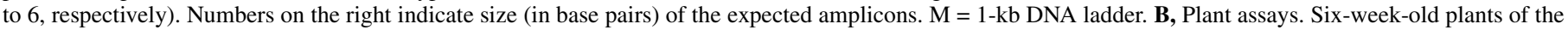

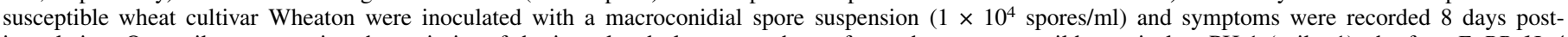

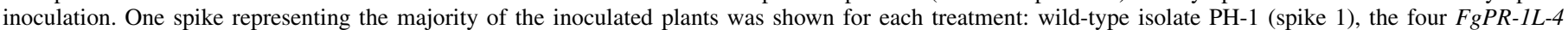

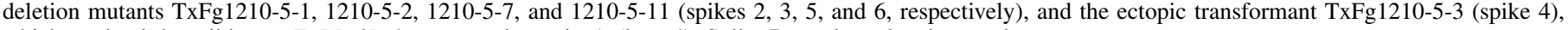
which retained the wild-type $F g P R-1 L-4$ gene, as shown in A (lane 4). Spike $7=$ uninoculated control. 
collected from 10 replicates with the total number of inoculated spikelets $>100$ per treatment) was 0.32 and 0.28 for the wild-type isolate and the ectopic transformant, respectively, but was only 0.06 to 0.08 for the four $\Delta f g p r-1 l-4$ mutants (Supplementary Table S5). The standard deviation of the averages was 0.10 and 0.13 for the wild type and the ectopic transformant, respectively, and 0.05 to 0.07 for the four $\Delta f g p r-1 l-4$ mutants. A $t$ test confirmed that the differences between the wild type and the four $\Delta f g p r-1 l-4$ mutants were all significant at $P<0.05$, whereas no significant differences were observed between the wild type and the ectopic transformant. The fact that the four independent $\Delta f g p r-1 l-4$ transformants showed the same reduced virulence phenotype in contrast to the ectopic control suggested strongly that the reduced virulence was caused by the targeted deletion of the $F g P R-1 L-4$ gene, less likely due to secondary mutations induced by the transformation procedures. Nevertheless, we will pursue a complementation test using the Geneticin-based cotransformation system (Desjardins et al. 2004) to further consolidate the virulence function of the $F g P R-1 L-4$ gene.

The same inoculation procedures were also used for virulence assays on the resistant wheat cultivar. None of the treatments resulted in bleached spikelets on Sumai 3. At 8 dpi, disease symptoms were observed as brown spots or partial necrosis that appeared to be similar between individual treatments (Supplementary Fig. S2). Different criteria need to be established to identify statistically significant differences (if any) in virulence on resistant wheat.

Targeted deletion experiments were also done for $F g P R-1 L-1,-2$, and -3 and several deletion mutants were obtained for these three genes as well. No apparent differences in virulence were observed between any of these deletion mutants and the wild type in plant assays (data not shown). Some $\Delta f g p r-1 l-3$ mutants were found to produce "clumped" perithecia on carrot agar plates much more frequently than the wild type. This phenotype was similar to those of the mating type gene deletion mutants of the fungus, as described previously (Desjardins et al. 2004), but additional experiments will be needed to evaluate the impact of the targeted deletion of the $F g P R-1 L-3$ gene on sexual reproduction of the fungus.

\section{DISCUSSION}

Although the PR-1 protein was first identified from plants (Van Loon and Van Kammen 1970), its homologs have been found widely in other eukaryotic organisms, including humans, animals, and fungi (Gibbs et al. 2008; Henriksen et al. 2001; Schuren et al. 1993). To date, studies on these nonplant PR-1L proteins are mainly devoted to human and animal systems in which the terms CAP and $\mathrm{SCP} / \mathrm{Tpx}$ 1/Ag5/PR-1/Sc7 have been introduced to define PR-1L proteins identified from various human or animal species (Asojo et al. 2011; Cantacessi et al. 2012; Gibbs et al. 2008). In contrast, much less attention has been paid to PR-1L proteins in fungi. Until now, there is only one case study available for filamentous ascomycetes that describes the identification of a PR-1L protein (Fpr1) from $F$. oxysporum $\mathrm{f}$. sp. lycopersici with a focus on mammalian hosts of the fungus (Prados-Rosales et al. 2012). In this work, we performed a comprehensive analysis of all PR-1L proteins encoded in the genome of $F$. graminearum and attempted to characterize their function in virulence on host plants. To the best of our knowledge, this is the first report on functional analysis of PR-1L proteins in the $F$. graminearum-wheat pathosystem.

Sequence and structure analyses indicated that $\mathrm{FgPR}-1 \mathrm{~L}$ proteins share common features with plant PR-1 proteins, including the conserved PR-1 domain, with all four active sites and the unique three-dimensional structures. However, the six Cys residues highly conserved in plant PR-1 proteins are either partially or completely missing in FgPR-1L proteins. FgPR-1L-1 and -2 have only two and four, respectively, whereas FgPR-1L-3 and -4 have none (Fig. 1A). The six Cys residues are expected to form three disulfide bridges that stabilize the PR-1 fold (Fernández et al. 1997) but are not absolutely required to maintain the three-dimensional structure, as shown for the human Golgi-associated pathogenesis-related protein, which also lacks all six conserved Cys residues (Serrano et al. 2004). The consequences from lacking these Cys residues in a PR$1 \mathrm{~L}$ protein have not been addressed. We found that the monomeric "Cys-free" FgPR-1L-4 protein is more sensitive to proteolytic attack than the dimeric wheat TaPR-1-5 protein, which contains the six Cys residues (Fig. 5). It is also more sensitive to subtilisin than the monomeric wheat TaPR-1-1 protein, which also contains the six Cys residues (Lu et al. 2013). It is likely that the disulfide bridges in the PR-1 fold may contribute to resistance to certain proteases. More interestingly, one of the FgPR-1L proteins (i.e., FgPR-1L-2) was found to have a TM domain embedded in the CTE region (Fig. 1). This TM domain has not been reported for any PR-1L proteins in previous studies except for TaPR-1-RK-1 and TaPR-1-RK-2, the two chimeric proteins just identified from wheat that contain double PR-1 domains fused to a protein kinase (Lu et al. 2017).

At the amino acid level, the four FgPR-1L proteins have no significant overall similarities to each other despite sharing the conserved PR-1 fold. At the nucleotide level, the $F g P R-1 L$ genes differ greatly in genomic structure, mRNA processing, and $\mathrm{G}+\mathrm{C}$ content. Both FgPR-1-1 and -2 are located on chromosome 1 but the former contains two introns and the latter is intron free. Both $F g P R$ $1 L-3$ and -4 are located on chromosome 2 within a relatively close proximity (approximately $0.5 \mathrm{Mb}$ apart) but the former contains two introns and the latter has only one (Fig. 2). The leader sequence or the 5'UTR in the full-length $F g P R-1 L-1$ mRNA consists of $429 \mathrm{nt}$, which is much longer than those of the other three genes (60 to 190 nt). The $\mathrm{G}+\mathrm{C}$ content in the coding sequence of the $F g-P R-1 L-4$ gene is $62 \%$, which is much higher than those of other three genes (49 to 51\%). These results imply that the four FgPR-1L proteins may not have a common evolutionary origin (e.g., they may have arisen from independent vertical or horizontal gene transfer events) or they may have diverged greatly if they did, nevertheless, originate from a common ancestor.

Transcriptional analysis revealed that the $F g P R-1 L$ genes differ greatly in their spatial and temporal expression patterns. The expression of the $F g P R-1 L-1,-2$, and -3 genes is associated with certain tissue specificity, whereas the expression of the $F g P R-1 L-4$ gene appears to be nontissue-specific (Fig. 4A). The FgPR-1L-1, -2, and -4 genes are expressed with the same or very similar temporal expression patterns in the vegetative mycelia grown in $\mathrm{MM}$ or $\mathrm{CM}$ but the $F g P R-1 L-3$ gene is expressed predominantly in the vegetative mycelia grown in MM (Fig. 4B). The temporal expression patterns of $F g P R-1 L-2$ and -4 remain very similar when the fungus infects wheat but the expression of the $F g P R-1 L-1$ and -3 genes appears to be downregulated (Fig. 4C). These distinct expression patterns are likely due to the nucleotide composition of the mRNA leader of the $F g P R-1 L$ genes, as mentioned above, because it is known that the length and the content of the 5'UTR contributes to the regulation of both translation and transcription of the downstream gene (Mignone et al. 2002). It is notable that no apparent differences were observed in the temporal expression patterns of the $F g P R-1 L$ genes when the fungus infected resistant (Sumai 3) versus susceptible (Wheaton) wheat (Fig. 4C), suggesting that the $F g P R$ - $1 L$ genes are less likely involved in host-specific interactions. However, the $F g P R-1 L-1$ gene (FGSG_00569) was found to be upregulated in planta on a different FHB-susceptible wheat cultivar (Lu and Edwards 2016). Thus, it is likely that the expression of the $F g P R-1 L-1$ gene is responsive to certain host factors not necessarily associated with susceptibility to FHB.

Previous studies have identified a limited number of proteinaceous virulence factors from $F$. graminearum (Hou et al. 2002; Jonkers et al. 2012; Seong et al. 2005; Voigt et al. 2005; H. Zhang et al. 2016; Y.-Z. Zhang et al. 2016; Zheng et al. 2016) but none of them are secreted proteins, except for the lipase-like protein FGL1 (Voigt et al. 2005). In this study, we demonstrate that a small secreted protein like FgPR-1L-4 functions in virulence of the fungus on wheat. The reduction in virulence of the $\Delta$ fgpr-1l-4 
mutants is limited (e.g., reduced approximately $20 \%$ compared with the wild type based on the percentage of bleached spikelets on infected wheat heads at $8 \mathrm{dpi}$ ) (Fig. 6), suggesting that $F g P R-1 L-4$ may play a minor (although statistically significant) role in FHB. The molecular basis underlying FgPR-1L-4-mediated virulence remains to be elucidated. Our data suggested that the native FgPR$1 \mathrm{~L}-4$ protein is constitutively expressed in mycelia at high levels (Fig. 4) and is partially resistant to serine proteases such as subtilisin (Fig. 5). It will be interesting to investigate whether this protein provides any protection for invading hyphae from certain types of proteolytic attacks by plant defense mechanisms.

The deletion of either $F g P R-1 L-1$ or $F g P R-1 L-3$ did not cause reduced virulence, which appears to be consistent with the in planta expression patterns mentioned above. However, it remains to be determined whether these two $F g P R-1 L$ genes play any virulence roles in other F. graminearum-associated pathosystems, because the fungus also incites diseases on several different hosts in addition to wheat (Backhouse and Burgess 2002; Chen et al. 2006; Logrieco et al. 2002; Martinelli et al. 2004; Sutton 1982). Whether these two $F g P R-1 L$ genes play roles in other aspects of the fungal life cycle (e.g., sexual reproduction) also should be explored. $F g P R-1 L-1$ is expressed in perithecia with a level much higher than in the other three types of cells as mentioned above, which echoes an early report that the gene encodes a PR-1L protein (Sc7) in the basidiomycete $S$. commune that is specifically expressed in fruiting bodies (Schuren et al. 1993). The $\Delta f g p r-1 l-3$ mutants appears to be abnormal in the development of perithecia (data not shown). Unlike $F g P R-1 L-1$ and -3 , both $F g P R-1 L-2$ and -4 are expressed in planta with different expression patterns (Fig. 4). Deletion of the $F g P R$ $1 L-2$ gene did not affect virulence, while the deletion of the $F g P R$ $1 L-4$ gene (which is expressed at higher levels) resulted in partially reduced virulence. It is not known if there is any functional overlap between these two genes; a double mutant ( $\Delta$ fgpr- $1 l-2 / \Delta f g p r-1 l-4)$ is needed to address this possibility.

Phylogenetic analysis conducted in this study (Fig. 3) provided some clues for understanding the functions of FgPR-1L proteins. For example, the FgPR-1L-1 protein is closely related to those of entomopathogenic or mycoparasitic species, raising the possibility that the FgPR-1L-1 gene (which appears to be dispensable in FHB) may function in fungal competition with other microorganisms. The TM-containing FgPR-1L-2 protein is found in the same group (group II) with many economically or medically important ascomycete pathogens such as Botrytis cinerea and $C$. immitis, suggesting that PR-1L proteins may function in certain membrane-associated pathways, likely including those contributing to pathogenesis. The FgPR-1L-4 protein is found in the same branch as Fpr-1, which has been shown to be involved in virulence of $F$. oxysporum $\mathrm{f}$. sp. lycopersici on mammalian hosts (Prados-Rosales et al. 2012), suggesting a functional conservation of this group of PR-1L proteins in pathogenesis. Our attempts to examine cross-kingdom phylogeny and infer relationships between fungal and plant or human or animal PR$1 \mathrm{~L}$ proteins were unsuccessful. All bootstrapping analyses failed to produce a consensus tree with $>50 \%$ confidence (data not shown). However, $F g P R-1 L-1,-3$, and -4 and many fungal PR-1L proteinencoding genes contain introns like their counterparts in humans and animals, in contrast to plant $P R-1$ genes that all lack introns (Supplementary Table S6). This may suggest that fungal PR-1L proteins are evolutionarily closer to those of humans or animals than to their counterparts in plants.

In conclusion, we have demonstrated that the genome of the wheat head blight fungus $F$. graminearum encodes multiple PR-1L proteins that have distinct spatial and temporal expression patterns, and at least one of which functions in virulence on susceptible wheat. Further studies are needed to address the molecular mechanisms underlying the $F g P R$ - $1 L$-4-mediated virulence in FHB and the potential involvement of individual PR-1L proteins in other F. graminearum-related pathosystems or general aspects in the life of filamentous ascomycetes.

\section{ACKNOWLEDGMENTS}

We thank C. Steen and M. Prince for technical assistance.

\section{LITERATURE CITED}

Altschul, S. F., Madden, T. L., Schaffer, A. A., Zhang, J., Zhang, Z., Miller, W., and Lipman, D. J. 1997. Gapped BLAST and PSI-BLAST: A new generation of protein database search programs. Nucleic Acids Res. 25: 3389-3402.

Asojo, O. A., Koski, R. A., and Bonafe, N. 2011. Structural studies of human glioma pathogenesis-related protein 1. Acta Crystallogr. D Biol. Crystallogr. 67:847-855

Backhouse, D., and Burgess, L. W. 2002. Climatic analysis of the distribution of Fusarium graminearum, F. pseudograminearum and F. culmorum on cereals in Australia. Australas. Plant Pathol. 31:321-327.

Bai, G., and Shaner, G. 2004. Management and resistance in wheat and barley to Fusarium head blight. Annu. Rev. Phytopathol. 42:135-161.

Breen, S., Williams, S. J., Winterberg, B., Kobe, B., and Solomon, P. S. 2016. Wheat PR-1 proteins are targeted by necrotrophic pathogen effector proteins. Plant J. 88:13-25.

Bretthauer, R. K., and Castellino, F. J. 1999. Glycosylation of Pichia pastorisderived proteins. Biotechnol. Appl. Biochem. 30:193-200.

Brown, N. A., Urban, M., van de Meene, A. M., and Hammond-Kosack, K. E. 2010. The infection biology of Fusarium graminearum: Defining the pathways of spikelet to spikelet colonisation in wheat ears. Fungal Biol. 114:555-571.

Buerstmayr, H., Ban, T., and Anderson, J. A. 2009. TL mapping and markerassisted selection for Fusarium head blight resistance in wheat: A review. Plant Breed. 128:1-26.

Buerstmayr, M., Alimari, A., Steiner, B., and Buerstmayr, H. 2013. Genetic mapping of QTL for resistance to Fusarium head blight spread (type 2 resistance) in a Triticum dicoccoides $\times$ Triticum durum backcross-derived population. Theor. Appl. Genet. 126:2825-2834.

Cantacessi, C., Hofmann, A., Young, N. D., Broder, U., Hall, R. S., Loukas, A., and Gasser, R. B. 2012. Insights into SCP/TAPS proteins of liver flukes based on large-scale bioinformatic analyses of sequence datasets. PLoS One 7:e31164.

Carson, M. 1997. Ribbons. Methods Enzymol. 277:493-505.

Catlett, N., Lee, B.-N., Yoder, O. C., and Turgeon, B. G. 2003. Split-marker recombination for efficient targeted deletion of fungal genes. Fungal Genet. Newsl. 50:9-11.

Chen, X., Steed, A., Harden, C., and Nicholson, P. 2006. Characterization of Arabidopsis thaliana-Fusarium graminearum interactions and identification of variation in resistance among ecotypes. Mol. Plant Pathol. 7:391403.

Cuomo, C. A., Guldener, U., Xu, J. R., Trail, F., Turgeon, B. G., Di Pietro, A., Walton, J. D., Ma, L. J., Baker, S. E., Rep, M., Adam, G., Antoniw, J., Baldwin, T., Calvo, S., Chang, Y. L., Decaprio, D., Gale, L. R., Gnerre, S., Goswami, R. S., Hammond-Kosack, K., Harris, L. J., Hilburn, K., Kennell, J. C., Kroken, S., Magnuson, J. K., Mannhaupt, G., Mauceli, E., Mewes, H. W., Mitterbauer, R., Muehlbauer, G., Munsterkotter, M., Nelson, D., O’Donnell, K., Ouellet, T., Qi, W., Quesneville, H., Roncero, M. I., Seong, K. Y., Tetko, I. V., Urban, M., Waalwijk, C., Ward, T. J., Yao, J., Birren, B. W., and Kistler, H. C. 2007. The Fusarium graminearum genome reveals a link between localized polymorphism and pathogen specialization. Science 317:1400-1402.

Desjardins, A. E., Brown, D. W., Yun, S. H., Proctor, R. H., Lee, T., Plattner, R. D., Lu, S. W., and Turgeon, B. G. 2004. Deletion and complementation of the mating type (MAT) locus of the wheat head blight pathogen Gibberella zeae. Appl. Environ. Microbiol. 70:2437-2444.

Felsenstein, J. 1989. Mathematics vs. evolution: Mathematical evolutionary theory. Science 246:941-942.

Fernández, C., Szyperski, T., Bruyère, T., Ramage, P., Mösinger, E., and Wüthrich, K. 1997. NMR solution structure of the pathogenesis-related protein P14a. J. Mol. Biol. 266:576-593.

Gibbs, G. M., Roelants, K., and O'Bryan, M. K. 2008. The CAP superfamily: Cysteine-rich secretory proteins, antigen 5 , and pathogenesis-related 1 proteins-Roles in reproduction, cancer, and immune defense. Endocr. Rev. 29:865-897.

Goswami, R. S., and Kistler, H. C. 2004. Heading for disaster: Fusarium graminearum on cereal crops. Mol. Plant Pathol. 5:515-525.

Goswami, R. S., and Kistler, H. C. 2005. Pathogenicity and in planta mycotoxin accumulation among members of the Fusarium graminearum species complex on wheat and rice. Phytopathology 95:1397-1404.

Green, M. R., and Sambrook, J. 2012. Molecular Cloning: A Laboratory Manual 4th ed. Cold Spring Harbor Laboratory, Cold Spring Harbor, NY.

Henriksen, A., King, T. P., Mirza, O., Monsalve, R. I., Meno, K., Ipsen, H., Larsen, J. N., Gajhede, M., and Spangfort, M. D. 2001. Major venom 
allergen of yellow jackets, Ves v. 5: Structural characterization of a pathogenesis-related protein superfamily. Proteins 45:438-448.

Hou, Z., Xue, C., Peng, Y., Katan, T., Kistler, H. C., and Xu, J. R. 2002. A mitogen-activated protein kinase gene (MGV1) in Fusarium graminearum is required for female fertility, heterokaryon formation, and plant infection. Mol. Plant-Microbe Interact. 15:1119-1127.

Jansen, C., von Wettstein, D., Schafer, W., Kogel, K. H., Felk, A., and Maier, F. J. 2005. Infection patterns in barley and wheat spikes inoculated with wild-type and trichodiene synthase gene disrupted Fusarium graminearum. Proc. Natl. Acad. Sci. USA 102:16892-16897.

Jonkers, W., Dong, Y., Broz, K., and Kistler, H. C. 2012. The Wor1-like protein Fgp1 regulates pathogenicity, toxin synthesis and reproduction in the phytopathogenic fungus Fusarium graminearum. PLoS Pathog 8:e1002724.

Kazan, K., Gardiner, D. M., and Manners, J. M. 2012. On the trail of a cereal killer: Recent advances in Fusarium graminearum pathogenomics and host resistance. Mol. Plant Pathol. 13:399-413.

Kelley, L. A., Mezulis, S., Yates, C. M., Wass, M. N., and Sternberg, M. J. 2015. The Phyre2 web portal for protein modeling, prediction and analysis. Nat. Protoc. 10:845-858.

King, R., Urban, M., Hammond-Kosack, M. C., Hassani-Pak, K., and Hammond-Kosack, K. E. 2015. The completed genome sequence of the pathogenic ascomycete fungus Fusarium graminearum. BMC Genomics 16:544.

Leach, J., Lang, B. R., and Yoder, O. C. 1982. Methods for selection of mutants and in vitro culture of Cochliobolus heterostrophus. Microbiology 128:1719-1729.

Logrieco, A., Mule, G., Moretti, A., and Bottalico, A. 2002. Toxigenic Fusarium species and mycotoxins associated with maize ear rot in Europe. Eur. J. Plant Pathol. 108:597-609.

Lorenz, M., Hewing, B., Hui, J., Zepp, A., Baumann, G., Bindereif, A., Stangl, V., and Stangl, K. 2007. Alternative splicing in intron 13 of the human eNOS gene: A potential mechanism for regulating eNOS activity. FASEB J. 21:1556-1564.

Lu, S. 2014. $\mathrm{Zn}^{2+}$ blocks annealing of complementary single-stranded DNA in a sequence-selective manner. Sci. Rep. 4:5464.

Lu, S., and Edwards, M. C. 2016. Genome-wide analysis of small secreted cysteine-rich proteins identifies candidate effector proteins potentially involved in Fusarium graminearum-wheat interactions. Phytopathology 106:166-176.

Lu, S., Faris, J. D., and Edwards, M. C. 2017. Molecular cloning and characterization of two novel genes from hexaploid wheat that encode double PR-1 domains coupled with a receptor-like protein kinase. Mol. Genet. Genomics 292:435-452.

Lu, S., Faris, J. D., Sherwood, R., and Edwards, M. C. 2013. Dimerization and protease resistance: New insight into the function of PR-1. J. Plant Physiol. 170:105-110.

Lu, S., Faris, J. D., Sherwood, R., Friesen, T. L., and Edwards, M. C. 2014. A dimeric PR-1-type pathogenesis-related protein interacts with ToxA and potentially mediates ToxA-induced necrosis in sensitive wheat. Mol. Plant Pathol. 15:650-663.

Lu, S., Friesen, T. L., and Faris, J. D. 2011. Molecular characterization and genomic mapping of the pathogenesis-related protein $1(P R-1)$ gene family in hexaploid wheat (Triticum aestivum L.). Mol. Genet. Genomics 285:485-503.

Lu, S., Gillian Turgeon, B., and Edwards, M. C. 2015. A ToxA-like protein from Cochliobolus heterostrophus induces light-dependent leaf necrosis and acts as a virulence factor with host selectivity on maize. Fungal Genet. Biol. 81:12-24.

Lu, S., Lyngholm, L., Yang, G., Bronson, C., Yoder, O. C., and Turgeon, B. G. 1994. Tagged mutations at the Toxl locus of Cochliobolus heterostrophus by restriction enzyme-mediated integration. Proc. Natl. Acad. Sci. USA 91: 12649-12653.

Lu, S. W., Kroken, S., Lee, B. N., Robbertse, B., Churchill, A. C., Yoder, O. C., and Turgeon, B. G. 2003. A novel class of gene controlling virulence in plant pathogenic ascomycete fungi. Proc. Natl. Acad. Sci. USA 100:5980-5985.

Lu, S. W., Tian, D., Borchardt-Wier, H. B., and Wang, X. 2008. Alternative splicing: A novel mechanism of regulation identified in the chorismate mutase gene of the potato cyst nematode Globodera rostochiensis. Mol. Biochem. Parasitol. 162:1-15.

Marchler-Bauer, A., Bo, Y., Han, L., He, J., Lanczycki, C. J., Lu, S., Chitsaz, F., Derbyshire, M. K., Geer, R. C., Gonzales, N. R., Gwadz, M., Hurwitz, D. I., Lu, F., Marchler, G. H., Song, J. S., Thanki, N., Wang, Z., Yamashita, R. A., Zhang, D., Zheng, C., Geer, L. Y., and Bryant, S. H. 2017. CDD/ SPARCLE: Functional classification of proteins via subfamily domain architectures. Nucleic Acids Res. 45:D200-D203.

Martinelli, J. A., Bocchese, C. A. C., Xie, W., O'Donnell, K., and Kistler, H. C. 2004. Soybean pod blight and root rot caused by lineages of the Fusarium graminearum and the production of mycotozins. Fitopatol. Bras. 29:492-498.

Mignone, F., Gissi, C., Liuni, S., and Pesole, G. 2002. Untranslated regions of mRNAs. Genome Biol. 3:reviews0004.1-reviews0004.10.
O’Leary, J. M., Radcliffe, C. M., Willis, A. C., Dwek, R. A., Rudd, P. M., and Downing, A. K. 2004. Identification and removal of O-linked and noncovalently linked sugars from recombinant protein produced using Pichia pastoris. Protein Expr. Purif. 38:217-227.

Prados-Rosales, R. C., Roldan-Rodriguez, R., Serena, C., Lopez-Berges, M. S., Guarro, J., Martinez-del-Pozo, A., and Di Pietro, A. 2012. A PR-1like protein of Fusarium oxysporum functions in virulence on mammalian hosts. J. Biol. Chem. 287:21970-21979.

Proctor, R. H., Hohn, T. M., and McCormick, S. P. 1995. Reduced virulence of Gibberella zeae caused by disruption of a trichothecene toxin biosynthetic gene. Mol. Plant-Microbe Interact. 8:593-601.

Rawat, N., Pumphrey, M. O., Liu, S., Zhang, X., Tiwari, V. K., Ando, K., Trick, H. N., Bockus, W. W., Akhunov, E., Anderson, J. A., and Gill, B. S. 2016. Wheat $F h b 1$ encodes a chimeric lectin with agglutinin domains and a pore-forming toxin-like domain conferring resistance to Fusarium head blight. Nat. Genet. 48:1576-1580.

Schuren, F. H., Asgeirsdottir, S. A., Kothe, E. M., Scheer, J. M., and Wessels, J. G. 1993. The Sc7/Sc14 gene family of Schizophyllum commune codes for extracellular proteins specifically expressed during fruit-body formation. J. Gen. Microbiol. 139:2083-2090.

Seong, K., Hou, Z., Tracy, M., Kistler, H. C., and Xu, J. R. 2005. Random insertional mutagenesis identifies genes associated with virulence in the wheat scab fungus Fusarium graminearum. Phytopathology 95:744-750.

Serrano, R. L., Kuhn, A., Hendricks, A., Helms, J. B., Sinning, I., and Groves, M. R. 2004. Structural analysis of the human Golgi-associated plant pathogenesis related protein GAPR-1 implicates dimerization as a regulatory mechanism. J. Mol. Biol. 339:173-183.

Shaner, G. E. 2003. Epidemiology of Fusarium head blight of small grain cereals in North America. Pages 84-119 in: Fusarium Head Blight of Wheat and Barley. K. J. Leonard and W. R. Bushnell, eds. The American Phytopathological Society Press, St. Paul, MN.

Sutton, J. C. 1982. Epidemiology of wheat head blight and maize ear rot caused by Fusarium graminearum. Can. J. Plant Pathol. 4:195-209.

Szyperski, T., Fernández, C., Mumenthaler, C., and Wüthrich, K. 1998. Structure comparison of human glioma pathogenesis-related protein GliPR and the plant pathogenesis-related protein P14a indicates a functional link between the human immune system and a plant defense system. Proc. Natl. Acad. Sci. USA 95:2262-2266.

Thompson, J. D., Gibson, T. J., Plewniak, F., Jeanmougin, F., and Higgins, D. G. 1997. The CLUSTAL_X windows interface: Flexible strategies for multiple sequence alignment aided by quality analysis tools. Nucleic Acids Res. 25:4876-4782.

Turgeon, B. G., Condon, B., Liu, J., and Zhang, N. 2010. Protoplast transformation of filamentous fungi. Methods Mol. Biol. 638:3-19.

Urban, M., King, R., Hassani-Pak, K., and Hammond-Kosack, K. E. 2015. Whole-genome analysis of Fusarium graminearum insertional mutants identifies virulence associated genes and unmasks untagged chromosomal deletions. BMC Genomics 16:261.

van Loon, L. C., Rep, M., and Pieterse, C. M. J. 2006. Significance of inducible defense-related proteins in infected plants. Annu. Rev. Phytopathol. 44:135-162.

Van Loon, L. C., and Van Kammen, A. 1970. Polyacrylamide disc electrophoresis of the soluble leaf proteins from Nicotiana tabacum var. "Samsun" and "Samsun NN". II. Changes in protein constitution after infection with tobacco mosaic virus. Virology 40:199-211.

van Loon, L. C., and van Strien, E. A. 1999. The families of pathogenesisrelated proteins, their activities, and comparative analysis of PR-1 type proteins. Physiol. Mol. Plant Pathol. 55:85-97.

Voigt, C. A., Schafer, W., and Salomon, S. 2005. A secreted lipase of Fusarium graminearum is a virulence factor required for infection of cereals. Plant 42:364-375.

Walter, S., Nicholson, P., and Doohan, F. M. 2010. Action and reaction of host and pathogen during Fusarium head blight disease. New Phytol. 185:54-66.

Xu, X., and Nicholson, P. 2009. Community ecology of fungal pathogens causing wheat head blight. Annu. Rev. Phytopathol. 47:83-103.

Zhang, H., Li, B., Fang, Q., Li, Y., Zheng, X., and Zhang, Z. 2016. SNARE protein FgVam7 controls growth, asexual and sexual development, and plant infection in Fusarium graminearum. Mol. Plant Pathol. 17:108-119.

Zhang, Y.-Z., Chen, Q., Liu, C.-H., Liu, Y.-B., Yi, P., Niu, K.-X., Wang, Y.-Q., Wang, A.-Q., Yu, H.-Y., Pu, Z.-E., Jiang, Q.-T., Wei, Y.-M., Qi, P.-F., and Zheng, Y.-L. 2016. Chitin synthase gene FgCHS8 affects virulence and fungal cell wall sensitivity to environmental stress in Fusarium graminearum. Fungal Biol. 120:764-774.

Zheng, W., Zheng, H., Zhao, X., Zhang, Y., Xie, Q., Lin, X., Chen, A., Yu, W., Lu, G., Shim, W. B., Zhou, J., and Wang, Z. 2016. Retrograde trafficking from the endosome to the trans-Golgi network mediated by the retromer is required for fungal development and pathogenicity in Fusarium graminearum. New Phytol. 210:1327-1343. 